\title{
ARTICLE OPEN Orally desensitized mast cells form a regulatory network with Treg cells for the control of food allergy
}

Yoshihiro Takasato $^{1,2}$, Yosuke Kurashima ${ }^{10}{ }^{1,3,4,5,6,7}$, Masahiro Kiuchi ${ }^{8}$, Kiyoshi Hirahara ${ }^{8}$, Sayuri Murasaki ${ }^{1,4}$, Fujimi Arai $^{1,4}$, Kumi Izawa $^{9}$, Ayako Kaitani ${ }^{9}$, Kaoru Shimada ${ }^{1,4}$, Yukari Saito ${ }^{3}$, Shota Toyoshima ${ }^{10}$, Miho Nakamura ${ }^{1}$, Kumiko Fujisawa ${ }^{1}$, Yoshimichi Okayama ${ }^{10}$, Jun Kunisawa ${ }^{4,7}$, Masato Kubo ${ }^{11,12}$, Naoki Takemura ${ }^{3,4,13}$, Satoshi Uematsu ${ }^{3,4,14}$, Shizuo Akira ${ }^{15,16}$, Jiro Kitaura ${ }^{9}$, Takao Takahashi², Toshinori Nakayama ${ }^{8}$ and Hiroshi Kiyono ${ }^{1,2,5,6,8}$

Oral immunotherapy (OIT) is an effective approach to controlling food allergy. Although the detailed molecular and cellular mechanisms of OIT are unknown currently, they must be understood to advance the treatment of allergic diseases in general. To elucidate the mechanisms of OIT, especially during the immunological transition from desensitization to allergy regulation, we generated a clinical OIT murine model and used it to examine immunological events of OIT. We found that in mice that completed OIT successfully, desensitized mast cells (MCs) showed functionally beneficial alterations, such as increased induction of regulatory cytokines and enhanced expansion of regulatory T cells. Importantly, these regulatory-T-cell-mediated inhibitions of allergic responses were dramatically decreased in mice lacking OIT-induced desensitized MC. Collectively, these findings show that the desensitization process modulates the activation of MCs, leading directly to enhanced induction of regulatory-T-cell expansion and promotion of clinical allergic unresponsiveness. Our results suggest that efficiently inducing regulatory MCs is a novel strategy for the treatment of allergic disease.

Mucosal Immunology (2021) 14:640-651; https://doi.org/10.1038/s41385-020-00358-3

\section{INTRODUCTION}

The numbers of patients with allergic diseases have increased worldwide, and about $30 \%$ of adults and about $50 \%$ of infants now experience allergic diseases such as hay fever and food allergy., About $5 \%$ of children have severe food allergy; the lack of curative treatments means that these children require intensive management to avoid intake of food allergens. ${ }^{1,2}$ The clinical signs of food allergic reaction are vomiting, diarrhea, and occasionally life-threatening anaphylaxis. ${ }^{1,2}$ IgE-mediated anaphylaxis is associated with gastrointestinal symptoms, including watery diarrhea, in $25-30 \%$ of cases. ${ }^{3,4}$

The central and pathological pathways of those allergic signs are mediated by mast cells (MC) $)^{5}$ and their derived mediators, including histamine, serotonin, sphingolipids, and leukotrienes, after MC degranulation induced through the cell surface complexing of FceR and antigen- specific lgE. Increased numbers of MCs in the gastrointestinal tract and their activation increases intestinal epithelial permeability, leading to the loss of electrolytes and water (diarrhea) and increasing vasopermeability; these factors potentially can cause systemic anaphylaxis. ${ }^{7}$ Likewise, systemic mastocytosis with gastrointestinal symptoms (e.g., watery allergic diarrhea) increases the risk of severe anaphylaxis. ${ }^{8}$

Inhibition of MC degranulation or blockade of the corresponding receptors of MC-derived mediators (e.g., histamine and leukotrienes) is a widely accepted symptomatic therapy. ${ }^{9}$ In addition, Th2 cytokines produced by MCs, such as IL- 4 and IL-5, augment the Th2 response. ${ }^{10} \mathrm{IL}-4$ release increases Th2 cell induction simultaneously with lgE production. ${ }^{10}$ Therefore, degranulation of, and pathogenic IL-4 production by, MCs are essential targets for the treatment of allergic diseases. Accumulation of MCs in the local mucosa, such as that of the gastrointestinal tract and colon, is often observed during food-antigen-induced allergic diarrhea. ${ }^{11,12}$ Inhibition of MC accumulation at the local mucosa is an attractive strategy for regulating the allergic reactions associated with food antigens. ${ }^{1,12}$

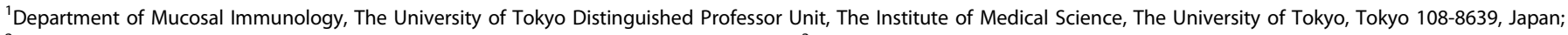

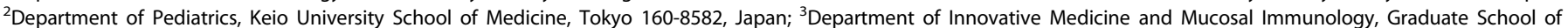

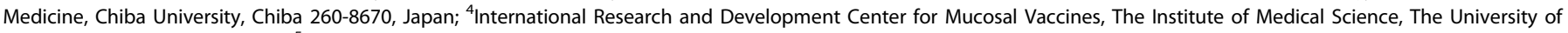

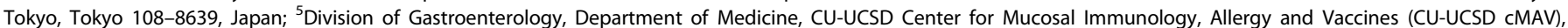

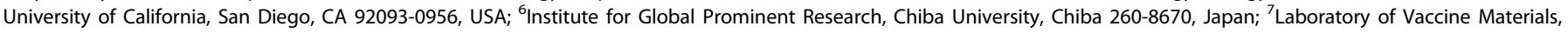

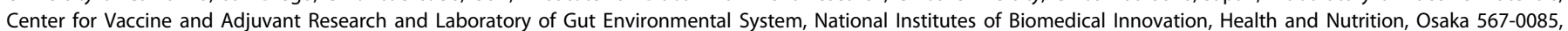

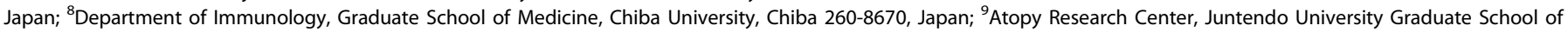

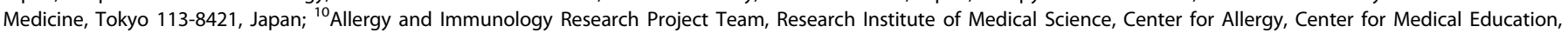

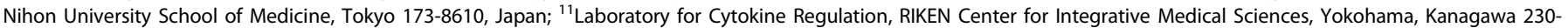

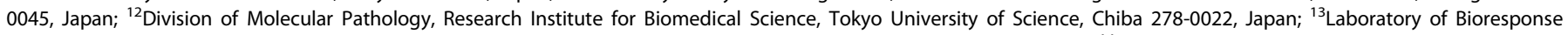

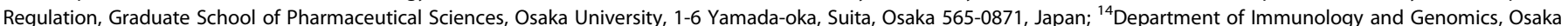

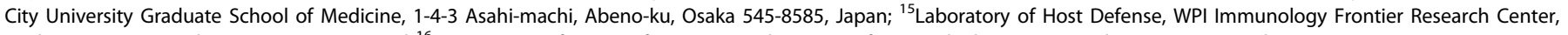
Osaka University, Osaka 565-0871, Japan and ${ }^{16}$ Department of Host Defense, Research Institute for Microbial Diseases, Osaka University, Osaka 565-0871, Japan Correspondence: Yosuke Kurashima (yosukek@ims.u-tokyo.ac.jp) or Hiroshi Kiyono (kiyono@ims.u-tokyo.ac.jp)

These authors contributed equally: Yoshihiro Takasato, Yosuke Kurashima
}

Received: 13 January 2020 Revised: 9 October 2020 Accepted: 21 October 2020

Published online: 10 December 2020 
Allergen-specific immunotherapy-especially subcutaneous or sublingual administration of allergens-effectively reduces allergic reactions in atopic dermatitis and rhinitis. ${ }^{13}$ Allergen desensitization via the oral route-oral immunotherapy (OIT) - is considered as an effective way of controlling food allergy. ${ }^{14,15}$ However, the underlying cellular and molecular mechanisms of OIT are still lacking in terms of long-term efficacy and safety; thus, elucidation of detailed OIT-mediated immunological events is required to develop and improve OIT-based fundamental treatment of allergic diseases. In addition, most published mechanisms have been based on peripheral blood studies that have analyzed responsiveness to allergens by using markers of degranulation (e.g., CD203) of basophils, ${ }^{16}$ and limited information is available regarding the role of gut mucosa and its associated mucosal immune system.

OIT consists of an initial escalation phase (or acute desensitization), followed by a maintenance (or consolidation) phase. ${ }^{16,17}$ Successful desensitization of MCs by continuous treatment with an allergen is essential for limiting the allergic reaction and leads to the establishment of allergen unresponsiveness (tolerance). ${ }^{18}$ The OIT protocol that was initially proposed and adopted was to increase the threshold of reactivity to the allergen by stimulation with a subthreshold dose, gradually escalating the amount given. ${ }^{18}$ However, the precise mechanisms of immunological transition especially from the initial phase of OIT to the maintenance or consolidation phase to induce unresponsiveness have not been carefully elucidated. Comparison of the characteristics of local MCs in the allergic state and in OIT is required for us to understand the mechanisms of the OIT-induced desensitized condition and to evaluate the efficiency of allergy control by OIT. Previous studies have revealed the novel functions of MCs that acquire immunomodulatory roles by producing regulatory cytokines (e.g., IL-2, IL-10). ${ }^{19,20}$ However, there are technical and ethical difficulties in studying cellular mechanisms in human subjects about mucosal tissues. To overcome these problems, several studies have used an OIT mouse model that might provide important new insights into OIT effects in local tissues (e.g., the intestinal tract), focusing on modulation of the functions of effector cells, especially MCs. Therefore, elucidation of detailed mechanisms of OIT-mediated desensitization system is required for fundamental treatment of allergic diseases.

Here, to reveal the contribution and functions of MCs in immunological transition from allergic promoter to suppressor during the initial phase of OIT in the gut mucosal compartment, we established an OIT murine model that mimicked clinical OIT to characterize the intestinal desensitized-MC-mediated suppression of food allergy. We show the immunoregulatory roles of desensitized regulatory MCs upon OIT in promoting clinical unresponsiveness by the direct induction of regulatory-T-cell (Treg) population expansion. We have uncovered novel roles for orally desensitized regulatory MCs in their involvement in longlasting oral unresponsiveness.

\section{RESULTS}

Development of OIT model for control of allergic diarrhea

Food allergy is a type I allergic reaction induced by $M C$ activation. ${ }^{17}$ Increased numbers of MCs and their activation in the mucosal compartment of the intestine enhance gastrointestinal permeability, causing watery diarrhea and allergen dissemination to the systemic compartment, where the allergens become triggers for anaphylaxis. ${ }^{4}$ To evaluate the immunological machinery of intestinal MCs in food allergy, we sought to generate OVAinduced allergic diarrhea in two murine models of MC deficiency, namely BALB/C back-crossed Kit ${ }^{W-s h / W-s h}$ mice and Mas-TRECK mice; the Mas-TRECK model was derived through continuous administration of diphtheria toxin. ${ }^{21,22}$ Oral challenge with OVA failed to elicit signs of allergic diarrhea in either strain of
MC-deficient mice, whereas identically challenged wild-type mice developed severe allergic diarrhea (Supplementary Fig. 1 a-c). When we discontinued the administration of diphtheria toxin for MC depletion to Mas-TRECK mice, the mice started showing allergic diarrhea after oral challenge with OVA (Supplementary Fig. 1c). In addition, anti-lgE treatment suppressed allergic diarrhea (data not shown). This series of experiments directly indicated the indispensable roles of IgE-mediated $M C$ activations in the development of allergic diarrhea.

Next, to establish an optimal OIT protocol for the control of pathological and clinical intestinal signs of food allergy in wildtype Balb/c mice, we tested a OIT protocol involving dose escalation of heated OVA (maximum dose, $25 \mathrm{mg}$ ) (Supplementary Fig. 2a). ${ }^{18,23}$ Our data indicated that dose-escalation OIT efficiently inhibited watery allergic diarrhea in this murine model (Supplementary Fig. $2 \mathrm{~b}$ and $\mathrm{c}$ ).

We further categorized the severity of antigen-induced allergic diarrhea according to three clinical criteria-no change, soft/ unformed, and liquid diarrhea-on the basis of the water content (Supplementary Fig. 2d and e) and evaluated in detail the efficacy of successful OIT treatment (Fig. 1). In the dose-escalation, OIT group watery diarrhea development was inhibited upon allergen oral challenge, and about $70 \%$ of mice showed no change in the feces (Fig. $1 \mathrm{a}$ and b). In contrast, over $80 \%$ of mice in which allergy was provoked and OIT was not given developed soft to liquid diarrhea. Furthermore, the percentage of MCs was significantly lower in the OIT group than in the allergy group ( $P<0.05$, Fig. 1C). But notably there were still significantly more MCs in these desensitized mice than in the intact group, our data indicated that the dose-escalation OIT protocol effectively created a desensitized state and thus prevented the development of orally induced allergic signs (i.e., severe diarrhea).

\section{Induction of orally desensitized mucosal MCs}

We next analyzed the activation status of intestinal MCs upon OIT. Levels of serum mast cell protease 1, which are correlated with the activation status of mucosal $\mathrm{MCs}_{1}{ }^{24}$ were significantly lower in OIT mice than in untreated mice $(P<0.01$, Fig. $1 \mathrm{~d})$. When gastrointestinal MCs were isolated and examined, the expression level of $\mathrm{CD63}$, associated with granule release, ${ }^{25}$ was also lower in the OIT group than in mice with allergic diarrhea (Fig. 1e). Furthermore, the frequency of degranulated MCs was significantly decreased to the normal level after OIT (Fig. 1f). Because IL-4 produced by MCs plays a pathological role in enhancing Th2-type responses, ${ }^{10}$ we sorted MCs from allergic and OIT mice and compared their gene expression of IL-4 (Fig. 1g). MCs from mice given OIT had significantly lower expression of $1 / 4$ than those from allergic mice (Fig. 1g). Thus, desensitized and reduced numbers of IL-4producing MCs were found in the gastrointestinal tract of OIT group compared with the allergic group, suggesting that OIT directly regulates local MCs and thus inhibits their acquisition of pathological characteristics. These results further suggest that orally administered allergen can directly control and desensitize pathogenic MCs.

Simultaneous induction of regulatory T-cells and desensitized MCs by OIT

Upon dose-escalation OIT, continuous administration of allergen is generally required for maintenance of oral unresponsiveness and continuing inhibition of allergic signs. ${ }^{13}$ We therefore expected that continuous administration of allergen would also be required for maintenance of desensitization of MCs, so we examined whether continued or discontinued oral administration of allergen was required for the maintenance phase of OIT (Fig. 2a). When OVA administration to OIT groups was stopped after desensitization had been induced by the initial OIT treatment, mice showed a reoccurrence of allergic diarrhea, which was correlated with a significant increase in the percentage of 


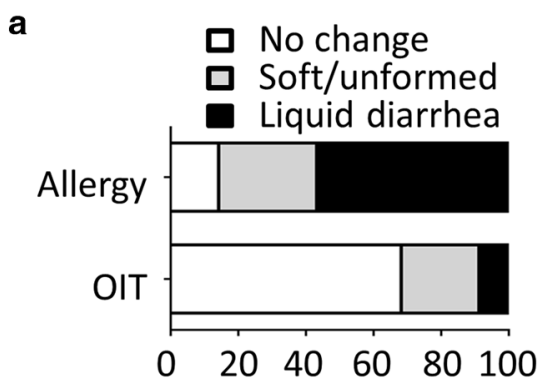

(\%)

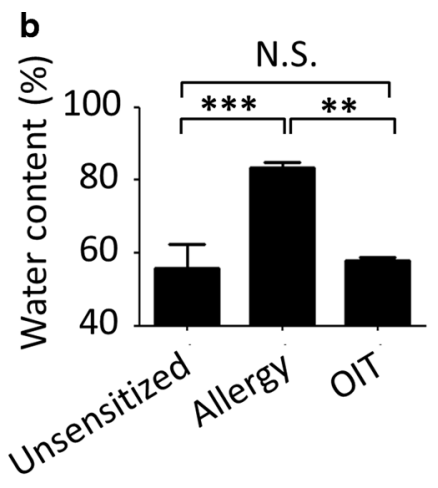

C

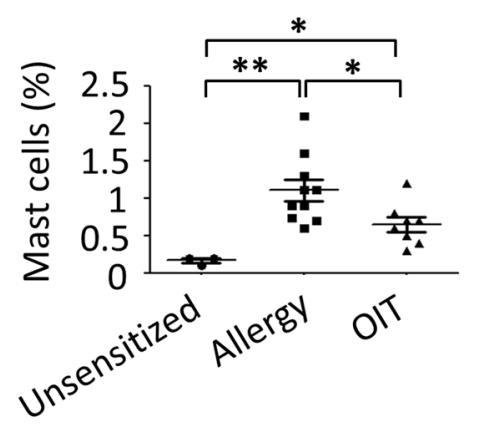

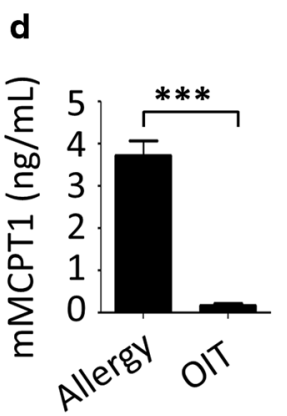
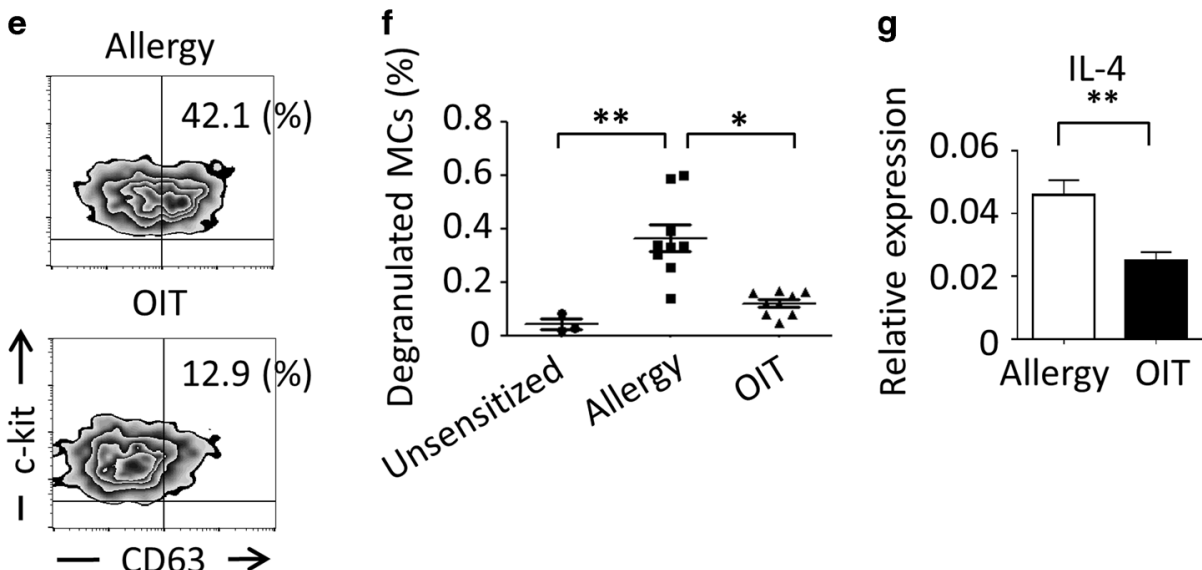

Fig. 1 Oral immunotherapy (OIT) desensitizes mast cells in local intestinal mucosa. a BALB/c mice showing allergic diarrhea were treated by OIT protocols or left untreated and the status of their stools was evaluated (Allergy, $n=15$; OIT $n=22$ ). $\mathbf{b}$ The water content of the stools was measured (Unsensitized, $n=3$; Allergy, $n=6$; OIT, $n=4$ ), ** $P<0.01$, *** $P<0.001$. N.S. indicates not significant. c Percentages of colonic MCs were examined by flow cytometry. Cells were gated on $\mathrm{CD}_{4} 5^{+} \mathrm{c}-\mathrm{kit}^{+} \mathrm{Fc \varepsilon Rl \alpha}{ }^{+}$cells. Percentages of MCs among CD45 ${ }^{+}$cells are shown (Non-allergic, $n=3$; Allergy, $n=10$; OIT, $n=8$ ). ${ }^{*} P<0.05$, ${ }^{* *} P<0.01$. d Serum mouse mast cell protease- 1 (mMCPT1) concentrations were measured by ELISA. (Allergy, $n=5$; OIT, $n=4$ ). e CD63 expression on colonic MCs was examined by flow cytometry. Cells were gated on c-kit ${ }^{+}$ and FceRl $\alpha^{+}$cells and the percentages of $\mathrm{CD}^{+} 3^{+} \mathrm{MCs}$ among all MCs were determined by flow cytometry. Data are representative of nine mice. f CD63 ${ }^{+}$MCs among CD45 ${ }^{+}$cells are shown (Intact, $n=3$; Allergy, $n=9$; OIT, $n=9$ ). ${ }^{*} P<0.05,{ }^{*} P<0.01$. g IL-4 cytokine expression was analyzed by quantitative RT-PCR. Each result was normalized against the expression of Gapdh. Data are shown as means \pm SEM, $* P<0.05$. N.S., not significant.

$\mathrm{CD}^{+} 3^{+}$degranulated MCs (Fig. 2b-d). In contrast, continuous OVA administration consistently suppressed allergic watery diarrhea and maintained the desensitized status of MC degranulation (Fig. 2d). These results clearly indicated that continuous oral administration of allergen was indispensable for the maintenance of desensitized MCs in the intestinal tract.

OIT is known to induce the production of T cells with suppressor functions, such as Treg and $\operatorname{Tr} 1$ cells. $^{26,27}$ In addition to the induction of desensitized MCs by OIT, our results suggested that dose-escalation OIT would result in the generation of these regulatory-type $T$ cells. We therefore next examined the numbers of these two T-cell subsets. Although Tr1 cells with phenotypic characteristics of $\mathrm{CD}_{49 \mathrm{~b}^{+}} \mathrm{CD}_{2} 23^{+}$and $\mathrm{CD} 4^{+}$are involved in oral unresponsiveness, ${ }^{26}$ we found no alteration in the numbers of Tr1 cells in the OIT group compared with the untreated allergy group (Fig. 2e). In contrast, the percentage of Foxp3 ${ }^{+}$Treg cells was significantly increased in the OIT group compared with the allergy groups and then significantly reduced compared with the OIT group when oral administration of allergen was stopped (Fig. $2 \mathrm{f}$ and g). In our previous study, adoptive transfer of intestinal $\mathrm{CD} 25^{+} \mathrm{CD} 4^{+}$Treg cells to food-allergic mice suppressed allergic diarrhea, thus emphasizing the critical role of Treg cells in controlling the allergic symptom. ${ }^{28}$

To further confirm the requirement for Treg cells in the effectiveness of OIT, we gave anti-CD25 monoclonal antibody ${ }^{29}$ or control rat IgG Ab to OIT-treated mice (Fig. 3a). All mice that received anti-CD25 mAb, resulted in partial depletion of Treg from mucosal compartment (data not shown), showed a recurrence of allergic diarrhea (Fig. $3 \mathrm{~b}$ and c). In addition, anti-CD25 mAb treatment enhanced OVA-specific IgE production in OIT-treated mice; prior to anti-CD25 treatment, IgE antibody levels had been low (Fig. 3d).

Concomitantly to the expansion of mucosal Treg cells, we found expansion of the systemic Treg population in the peripheral blood and spleens of mice that received OIT treatment (Supplementary Fig. 3). These results indicate that OIT-mediated expansion of the circulating Treg population (possibly derived from mucosal compartments) contributes to the suppression of allergic reactions (e.g., systemic and skin symptoms); this suppression occurs through the reduction of both allergen-specific $\lg \mathrm{E}$ production and degranulation of MCs and basophils (Fig. 3d and Supplementary Fig. 3).

Desensitized MCs play a critical role in the regulation of allergic signs

In addition to the generation of desensitized MCs (Fig. 1), we found that OIT induced the production of Treg cells for the suppression of allergic diarrhea (Fig. 2f, g and 3). However, the mechanisms behind the relationship between the induction of desensitized MCs and Treg cells in OIT needed to be further 
a

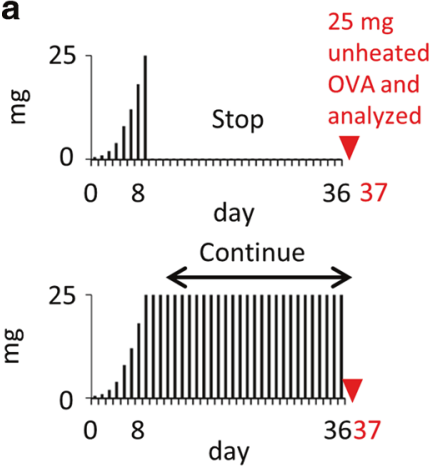

e

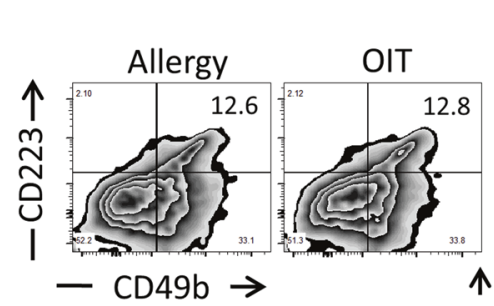

b
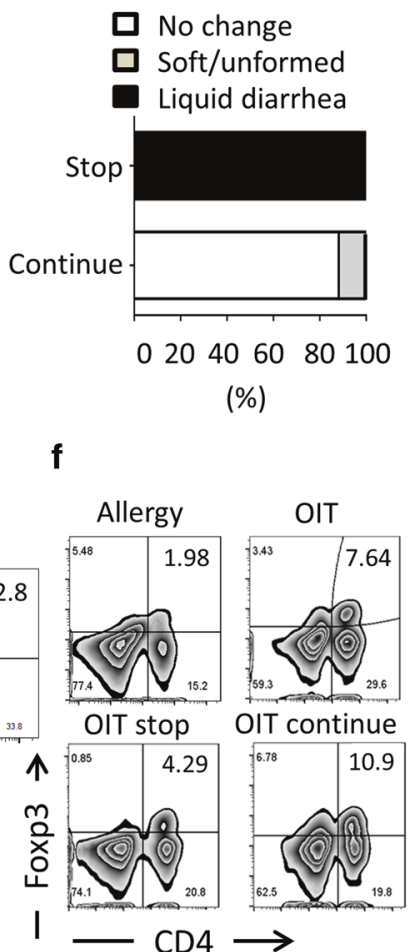

C

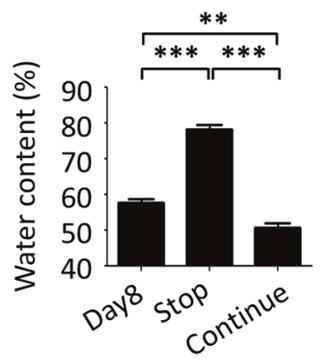

d

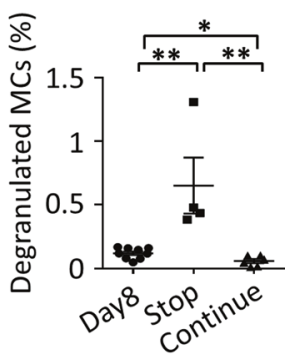

(\%)

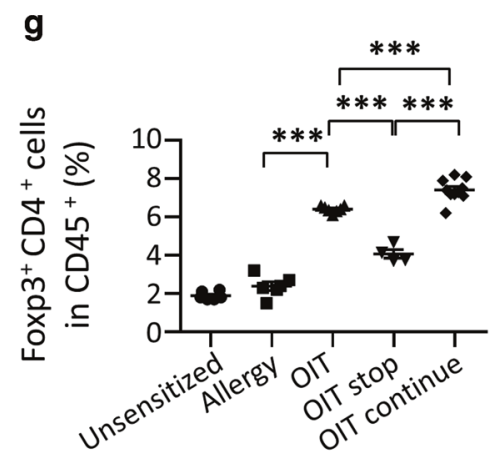

Fig. 2 Continuous exposure to allergen after successful oral immunotherapy (OIT) sustains the reduction in diarrhea and the regulatory T-cell response. a The protocol used in this experiment. Black bars indicate the amounts $(\mathrm{mg})$ of heated ovalbumin (OVA), and the red triangle indicates the oral administration of $25 \mathrm{mg}$ unheated OVA. b Status of mice stools upon unheated OVA administration was evaluated. (Stop OIT, $n=4$; continue OIT, $n=8$ ). c Water content of stools was measured (OIT [day 8], $n=4$; stop [day 37], $n=4$; continue: $n=4$ [day 37]). Data are shown as means $\pm \mathrm{SEM},{ }^{* *} P<0.01,{ }^{* *} P<0.001$. d CD63 ${ }^{+}$intestinal mast cells as a percentage of all CD45 $5^{+}$cells are shown (day 8 of OIT, $n=9$; day 37 of stop, $n=4$; continue, $n=4)$. e Cells were harvested from the colon and stained to evaluate the presence of Tr1 cells. Cells were gated on CD4. Number indicates percentage of $\mathrm{CD}_{22} 3^{+} \mathrm{CD} 49 \mathrm{~b}^{+} \mathrm{Tr} 1$ cells. Data are representative of at least three individuals. $\mathbf{f}$ and $\mathbf{g}$ Cells were gated on CD45 and percentages of Foxp $3^{+} \mathrm{CD}^{+} \mathrm{T}$ cells are shown. Representative FACS plots were shown and each dot represents an individual mouse. Data are shown as means \pm SEM, ${ }^{* * *} P<0.001$.

elucidated. An increase in the induction of tolerogenic dendritic cells (DCs) plays important role in the establishment of oral unresponsiveness. ${ }^{30}$ We therefore considered it important to elucidate whether DCs were involved in the increased production of Treg cells via desensitization of MCs. We first examined the possible involvement of desensitized MCs in the induction of DCs or increase in their populations, because MCs have been shown to play a role in the induction of tolerogenic DCs in tissue transplantation mouse model. ${ }^{31,32}$ We therefore examined the profiling of these DC subsets, such as Tim4 ${ }^{+} \mathrm{CD}_{11 \mathrm{c}^{+}} \mathrm{DCs}$, including pro-allergic subsets, and $\mathrm{CD}_{103^{+}} \mathrm{CD}_{11} \mathrm{~b}^{\text {neg }} \mathrm{CD} 11 \mathrm{c}^{+}$ tolerogenic DCs. ${ }^{33,34}$ Both OIT and allergic mice and found that the ratios of DC subsets did not differ significantly between the two groups of mice (Fig. 4a and b). Because our findings suggested that the properties of intestinal DCs were not altered by OIT, alternative pathways-including MC-mediated direct pathways-might be involved.

The novel properties of MCs in promoting Treg-cell-mediated suppression of papain-induced allergic inflammation have recently been elucidated. ${ }^{20}$ Accumulated evidence has further revealed the tolerogenic properties of MCs in any diseases (e.g., atopic dermatitis, asthma and graft-versus-host disease). ${ }^{35,36}$ Therefore, next, we examined whether desensitized MCs directly mediated Treg induction. We depleted MCs in Mas-TRECK mice during the OIT procedure (days 5 through 36 ) by giving diphtheria toxin (see Fig. 4c). Under normal conditions or in the allergic state, $\mathrm{MC}$ depletion did not reduce the percentage of Treg cells in the intestinal tract (Supplementary Fig. 4a); however, depletion of MCs during OIT led to a significant reduction in the percentage of Treg cells in the intestine compared with control group $(P<0.01$, Fig. $4 \mathrm{~d}$ and e), but not in the spleen and mesenteric lymph nodes (Supplementary Fig. 4b). Importantly, comparison of the quality of the Treg cells of OIT mice with and without MCs showed significant reductions in the production of inhibitory cytokines in the latter (e.g., IL-10 and TGF- $\beta$ ) (Fig. 4f). These findings suggested that OIT induces desensitized MCs, which mediate the induction and maintenance of Treg cells possessing suppressive properties such as inhibitory cytokine synthesis.

Functional modulation of pathogenic MCs by the desensitization process

To further elucidate whether OIT-induced desensitized MCs are involved in the induction and maintenance of Treg cells, we adopted an in vitro desensitization protocol. ${ }^{37,38}$ To generate desensitized MCs, about 95\% purified BMMC were utilized (Supplementary Fig. 5a and b) and lgE-bound BMMCs were prepared and treated with gradually increasing amounts of allergen, or model antigen (2,4-dinitrophenyl; DNP). The treatment induced desensitized MCs, because reduced surface expression of the degranulation-associated molecule CD63 and reduced release of degranulation-associated $\beta$-hexosaminidase compared with those in untreated allergic mice were noted (Fig. $5 a-c) .{ }^{25}$ These results are consistent with our in vivo data that OIT-desensitized MCs efficiently reduced surface CD63 expression (Fig. 1e and f).

As described above, not only degranulation of MCs but also the control of pathogenic Th2 responses mediated by elevated IL-4 production by these MCs (Fig. 1g) was important for allergy treatment. To further confirm this point, we examined IL-4 
a

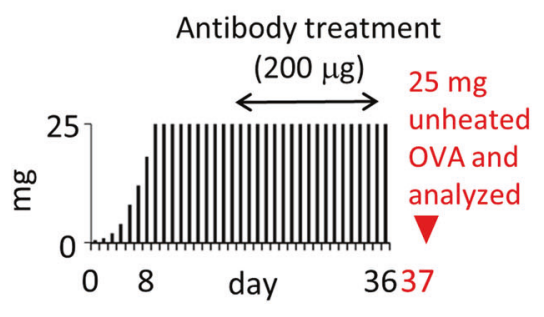

c

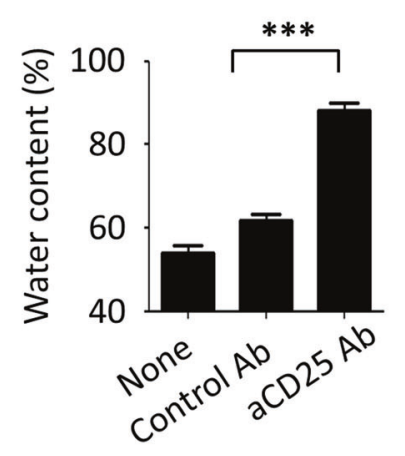

b
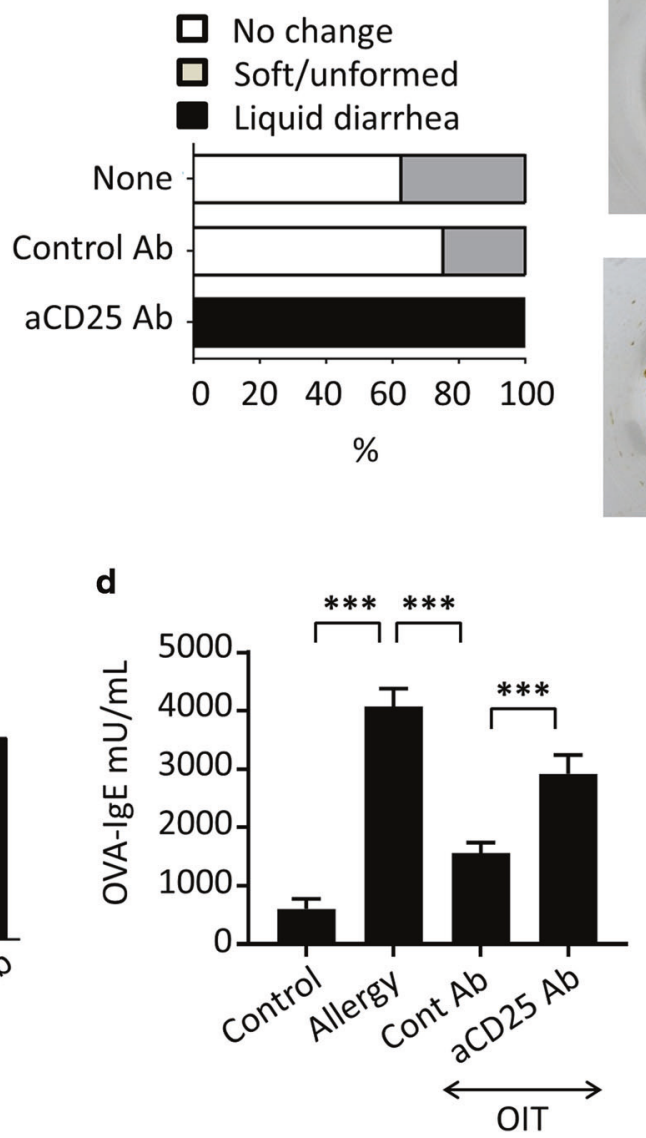

Control $\mathrm{Ab}$

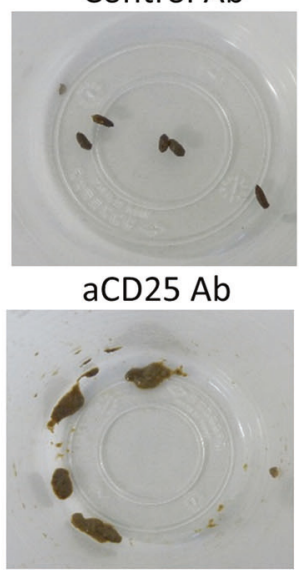

Fig. 3 Regulatory T cells are required for treatment of food allergy. a Experimental scheme. Black bars indicate the amounts (mg) of heated ovalbumin (OVA), and the red arrowhead indicates initiation of daily oral administration of 25 mg unheated OVA. b Mice receiving oral immunotherapy were treated with $100 \mu \mathrm{g}$ of anti-CD25 monoclonal antibody (aCD25) or left untreated (None) or treated with control antibody. Stool status was then evaluated, $n=3$. Data were representative of two independent experiments. c The water content of the stools in each treatment group was measured. Data are shown as means \pm SEM of $n=3,{ }^{* * *} P<0.001$. d Serum OVA-specific IgE was measured by using ELISA. Data are shown as means \pm SEM of $n=4-6,{ }^{* * *} P<0.001$.

expression levels in MCs desensitized by OIT and compared them with those in degranulated MCs from mice with allergic diarrhea. IL-4 expression by the desensitized MCs was significantly reduced by the OIT process (Fig. $5 \mathrm{~d}$ ). We further evaluated the shift in MCs from pathogenic (or pro-allergic) status to regulatory (desensitization) status by evaluating the histone modification status at Th2 cytokine gene loci-especially those encoding IL-4 and IL-13 (Fig. 5e). MCs were isolated from normal mice, mice with allergic diarrhea, and OIT mice. Control, activated, and desensitized MCs were examined (Fig. 5e). ChIP-Seq analysis revealed that the levels of histone $\mathrm{H} 3$ acetylated at Lys27 (H3K27Ac) were decreased around the promoter regions of the $/ 14$ and $/ 113$ gene loci after desensitization (Fig. 5e). This evidence clearly indicated that the in vitro desensitization process functionally and directly regulated degranulation of, as well as Th2 cytokine production by, MCs. These results imply that the desensitization procedure modulates allergic Th2-prone MCs to acquire unique, predictively immunoregulatory characteristics that promote clinical unresponsiveness.

Pivotal roles of desensitized MCs in expansion of Treg cell populations in an IL-2 dependent manner

On the basis of our in vitro and in vivo observations of a functional shift in MCs, which we predicted would be the acquisition of a regulatory function upon OIT (Figs. 4 and 5), we adopted an in vitro desensitization protocol ${ }^{37,38}$ to directly reveal Treg-cell expansion by OIT-induced desensitized MCs. To generate desensitized MCs, IgE-bound bone marrow (BM) MCs were prepared and treated with gradually increasing amounts of allergen.

Because our results had suggested that OIT-induced desensitized MCs were involved in the expansion of Treg cells (Fig. 4), this experiment aimed to directly address whether the desensitized MCs could expand Treg cells in an in vitro coculture system. CD4 ${ }^{+}$ $T$ cells were cultured with antigen -desensitized or allergic BMMCs (Fig. 6a). Foxp3 expression by these $\mathrm{CD}^{+} \mathrm{T}$ cells was then examined by FACS (Fig. 6a). Desensitized MCs, but not control or allergic MCs, expanded the Treg cell population (Fig. 6a). As reported previously, MCs lack the ability to present antigens. ${ }^{20}$ Indeed, desensitized MCs lacked the expression of MHC-II and costimulatory molecules (e.g., CD80), and their ability to induce the differentiation of Treg cells from naïve $\mathrm{CD}^{+}{ }^{+} \mathrm{T}$ cells was limited (Supplementary Fig. 6 and 7). These results suggest that secretory factors are involved in expansion of the Treg cell population by desensitized MCs. To explore this possibility, we performed a coculture experiment with a transwell assay (Fig. 6b). The assay revealed that secreting molecules from the desensitized regulatory MCs were involved in the induction of Treg cells, because physical separation of the desensitized MCs and the $\mathrm{CD}^{+} \mathrm{T}$ cells still resulted in the expansion of Treg cells (Fig. $6 \mathrm{~b}$ ).

To examine the molecular mechanisms underlying Treg induction by the desensitized MCs, we performed gene profiling 


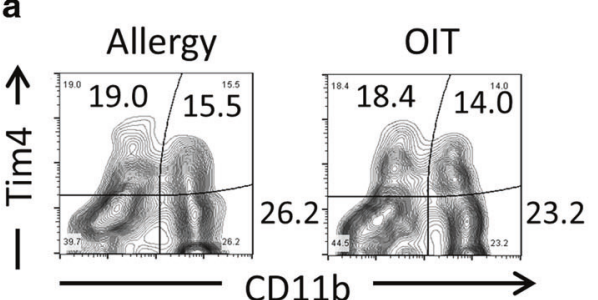

C

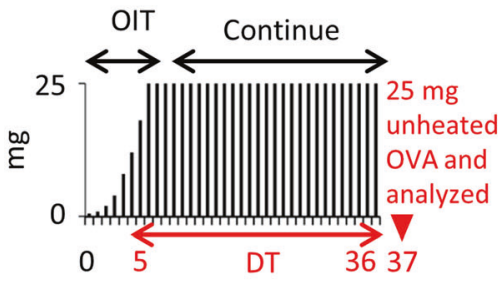

(day) b

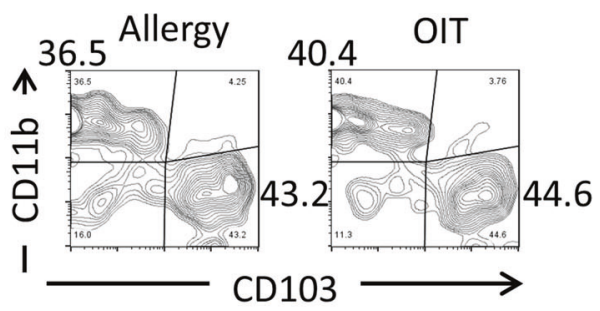

d Gated for CD45+

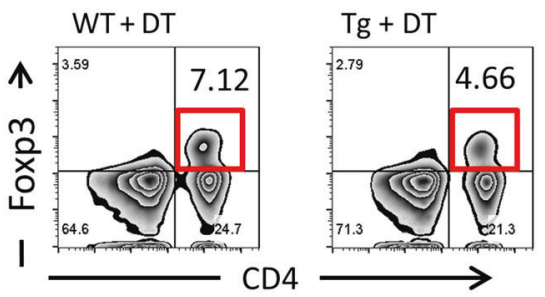

TGF- $\beta$

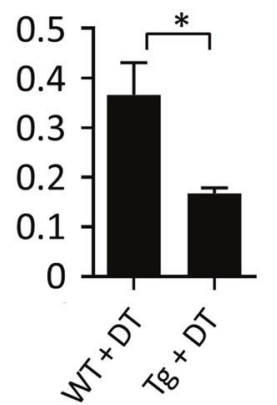

Fig. 4 Involvement of mast cells in expansion of Foxp3 Treg populations upon oral immunotherapy (OIT). a Tim4 and CD11b and (b) $\mathrm{CD} 11 \mathrm{~b}$ and $\mathrm{CD} 103$ were both gated for $\mathrm{CD} 11 \mathrm{c}^{+} \mathrm{CD} 45^{+}$and examined by flow cytometry. The numbers shown indicate the percentages of cell populations. Data represent three individual experiments. c Protocol used in this experiment. Black bars indicate the doses of heated ovalbumin (OVA), and the red triangle indicates the administration of $25 \mathrm{mg}$ of unheated OVA. Diphtheria toxin (DT) was administered to MasTRECK mice during OIT. $\mathbf{d}$ and e OIT mice (wild-type [WT] or Mas-TRECK transgenic [tg] mice) received DT from days 5 through 36, and Foxp3expressing Tregs were observed by flow cytometry on day 37 upon inoculation of unheated 25 mg of OVA. Data are gated for CD45 and representative of at least three individual experiments. Data are shown as means $\pm \mathrm{SEM},{ }^{* *} P<0.01 . \mathbf{f} \mathrm{CD} 25^{+} \mathrm{CD} 39^{+} \mathrm{CD} 103^{+} \mathrm{CD} 4^{+} \mathrm{T}$ cells were isolated, and IL-10 and TGF- $\beta$ gene expression was analyzed by quantitative RT-PCR. Data are shown as means \pm SEM, ${ }^{*} P<0.05$ (all groups, $n=$ 4).

of in vitro-activated and -desensitized MCs (Fig. 6c). Expression of the genes encoding several cytokines (IL-2, IL-6, IL-11 and IL-17d) was increased in the desensitized MCs (Fig. 6c). Furthermore, when we examined the actual production of these cytokines, the production of IL-2, but no other cytokines, was significantly increased by the desensitized regulatory MCs (Fig. $6 \mathrm{~d}$, e and data not shown). Importantly, we harvested MCs from human peripheral blood, desensitized them in vitro, and then assessed their production of IL-2 (Fig. 6f). These results revealed a trend $(P=0.145)$ of increased IL-2 production from desensitized human MCs when compared with sensitized human MCs. IL-2's roles in the induction and proliferation of Treg cells are well-known; ${ }^{39,40}$ therefore, next, we conducted IL-2 neutralizing experiments using cocultures of desensitized murine regulatory $\mathrm{MCs}$ and $\mathrm{CD}^{+}$ T cells. ${ }^{41}$ Anti-IL-2 neutralizing mAb greatly inhibited Treg-cell induction by desensitized regulatory MCs in vitro (Fig. $6 \mathrm{~g}$ ). These results clearly indicated that the desensitized regulatory MC-IL-2 pathway plays a critical role in Treg-cell induction in OIT-induced suppression (Fig. 4). Finally, we examined the expression of these regulatory cytokines by MCs isolated from the intestines of allergic and OIT mice. Importantly, quantitative RT-PCR analysis revealed significantly increased expression of IL-2 and IL-10 in orally desensitized lamina propria MCs $(P<0.05$, Fig. $6 \mathrm{~h})$.

\section{DISCUSSION}

OIT is an efficient desensitization treatment for food allergy. ${ }^{14,15}$ In the early stage of OIT, gradual dose escalation is required to suppress the degranulation of MCs and basophils. ${ }^{17}$ Previous studies have executed the OIT protocol before the onset of food allergy (i.e., in the pre-sensitization phase or naïve stage), thus leading to the induction of oral tolerance. ${ }^{42,43}$ However, in clinical practice, most patients are already sensitized and susceptible to food allergy, ${ }^{13-15}$ and OIT has only infrequently been used in foodallergic patients. ${ }^{13-15}$ Therefore, to understand the mechanistic relevance of allergy treatment through OIT in humans, it is important to develop an OIT treatment model for food allergy that better resembles the clinical situation.

Here, by developing a clinically relevant OIT murine model, we revealed a novel mechanistic immunological process in the intestinal mucosa upon successful OIT. Our OIT model indicated that dose escalation was more efficient than defined-dose 
a

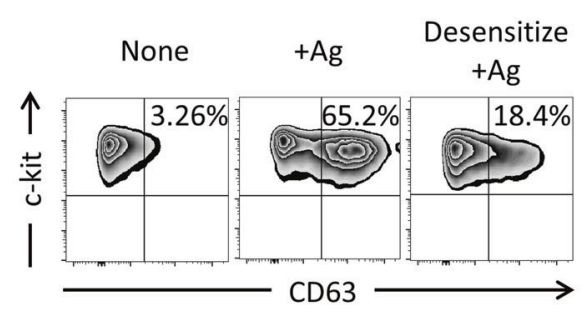

b

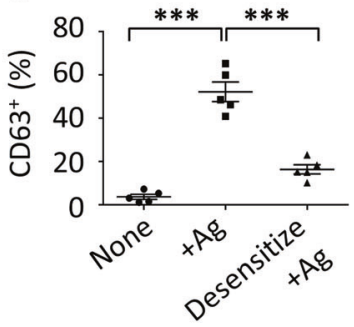

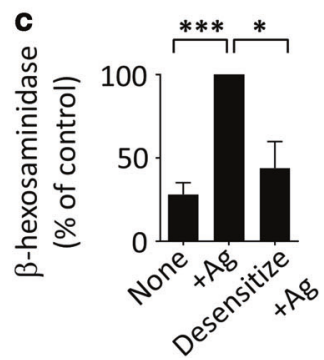

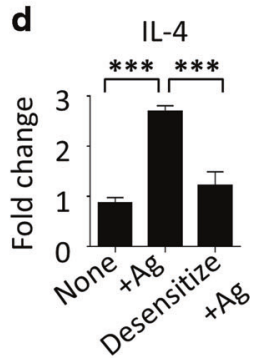

e

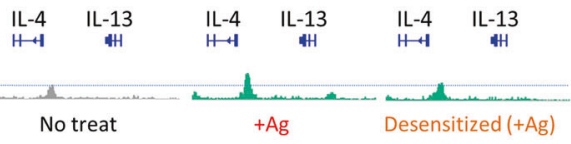

Fig. 5 Rapid desensitization controls pathogenic mast cell (MC)-mediated Th2 immunity. a and b DNP-lgE bound bone marrow MCs (BMMCs) were stimulated or desensitized with antigen (DNP-HSA). CD63 expression was observed by fluorescence-activated cell sorting. Percentages indicate CD63 ${ }^{+}$in whole BMMCs. ${ }^{* *} P<0.001$. c A $\beta$-hexosaminidase assay was performed. Data are expressed as differences from the value in undesensitized activated MCs (100\%) as a control. ${ }^{*} P<0.01,{ }^{* * *} P<0.001$. d IL-4 expression was examined by quantitative RTPCR. Data are expressed as differences from non-activated or desensitized MCs ("None") as a control (e) Chromatin immunoprecipitation was performed; acetylation levels of H3K27 of IL-4 and IL-13 promoters are shown.

treatment in desensitizing MCs (Supplementary Fig. 2). The functional characteristics of desensitized and immunosuppressive MCs had not been well studied, so we found and scrutinized the unique characteristics of desensitized MCs with regulatory functions (regulatory MCs) that play a major role in the establishment of oral unresponsiveness by OIT.

First, we revealed the importance of mucosal Treg cells in OIT. The relationship between increased Treg cell populations and successful OIT has been well documented; however, direct evidence of the requirement for Treg cells in preventing food allergy had not been presented. Here, by antibody depletion of both antigen-specific and -nonspecific populations, we examined the indispensable roles of Treg cells and clearly found that all mice developed severe diarrhea upon the reduction of Treg cell numbers (Fig. 3). In the context of Treg cell expansion, an increase in Treg cell numbers by the administration of low-dose IL-2 efficiently suppresses both allergy and auto-immune disease. ${ }^{44,45}$ Daily intraperitoneal injection of IL-2 for 5 days successfully expands the Treg cell population without affecting effector $\mathrm{T}$ cells. ${ }^{44}$ Our study revealed an increase in local IL-2-producing desensitized (or regulatory) MCs upon OIT, whereas a decrease in the abundance of these MCs simultaneously decreased Treg cell abundance at the local mucosa. These findings imply that continuous and optimal-dose antigen delivery by OIT leads to the induction of IL-2-producing regulatory MCs for efficient expansion of Treg cell populations. Despite the considerable debate regarding the functional and transcriptional heterogeneity and functional instability of Treg cells, these properties have important implications for Treg cell-based immunotherapy, ${ }^{46}$ particularly given that effective induction and maintenance of Treg cells is important for the acquisition of unresponsiveness in various allergic diseases, such as allergic rhinitis. ${ }^{13}$

In our current study, anti-CD25 antibody treatment in OIT mice led to the elimination of Tregs and thus the recurrence of allergic reactions and increased OVA-IgE production (Fig. 3). It is plausible that IL-10 and TGF $\beta$ derived from Treg cells directly suppress function of IgE-producing cells or remaining undesensitized $M C$ populations still residing in the OIT-treated mucosa, so that anti-
CD25 antibody treatment leads to the gastrointestinal sign of watery allergic diarrhea (Fig. 3e).

To further understand the role of the Treg network, we assessed possible crosstalk between Treg cells and $T$ follicular-cell populations including TFH, TFR, and TFH13, which have been shown to important in the control of IgE production. ${ }^{47,48}$ We found no significant changes in the T follicular-cell population in OIT mice treated with anti-CD25 antibody compared with control antibody (Supplementary Fig. 8a and b), indicating that Tregs had little or no effect on the expansion of $T$ follicular-cells in this model. Likewise, MC-depleted mice lacked significant changes in the T follicular-cell population (Supplementary Fig. 8a and b), demonstrating that the desensitized MC-Treg pathway dose not contribute to $\mathrm{T}$ follicular-cell -mediated $\lg \mathrm{E}$ production in this model.

Our current results indicate that suppression of Th2 cytokines through desensitization occurs simultaneously with the upregulation of IL-2 and IL-10 by desensitized (or regulatory) MCs. In some circumstances (e.g., dermatitis, asthma, and graft-versus-host disease), MCs possess immunosuppressive properties mediated by the production of immunoregulatory cytokines such as IL-2, IL10, IL-33, and TGF- $\beta .{ }^{19,20}$ Considering these previous results together with our current ones (Fig. 6), it is plausible to suggest that desensitized MCs behave as a form of regulatory cells producing these regulatory cytokines and categorized as regulatory MCs, and that they directly or indirectly (via the induction of Treg cells) suppress undesired allergic responses. MCs have also been shown to have a direct suppressive function, which is mediated in an IL-10-dependent manner. ${ }^{19}$ Skin allograft rejection is regulated by IL-10 derived from skin MCs. ${ }^{19} \mathrm{IL}-10$ derived from skin MCs educates DCs to induce Tregs. ${ }^{19} \mathrm{IL}-10$ from MCs is also involved in the maintenance of immune privilege in the bladder. ${ }^{49}$ These findings suggest that IL-10-producing MCs can behave as regulatory MCs for the control of undesired immune responses. We found here that, along with IL-2 expression, IL-10 expression was upregulated in OIT-treated MCs (Fig. 6g); thus, IL-2 and IL-10 dual synthesis in response to OIT-induced mucosal desensitization of MCs resulted in a duplex suppressive pathway of induction of 


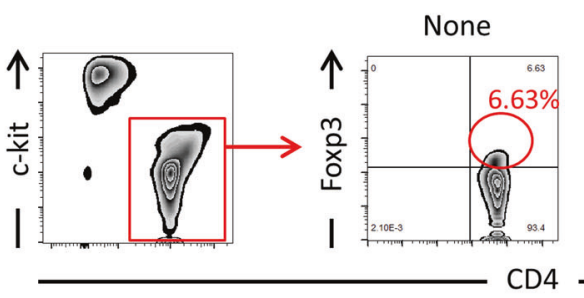

b

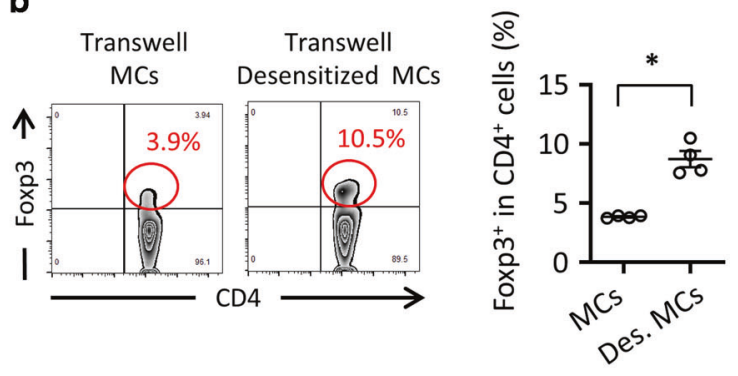

c

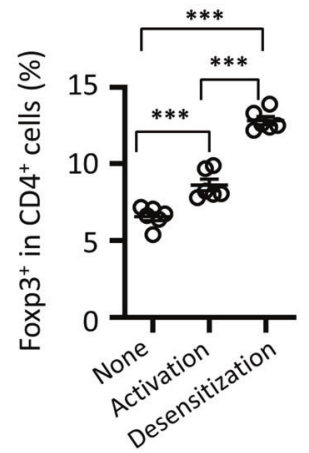

Desensitization

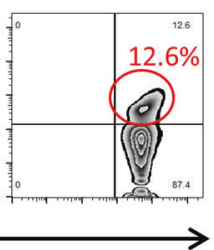

d

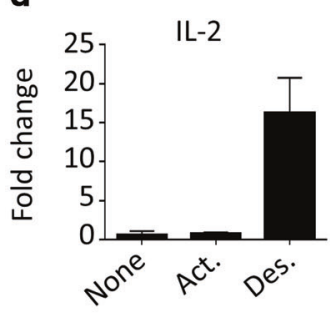

Activation

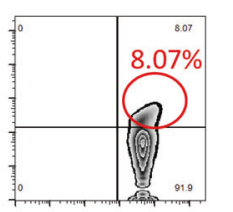

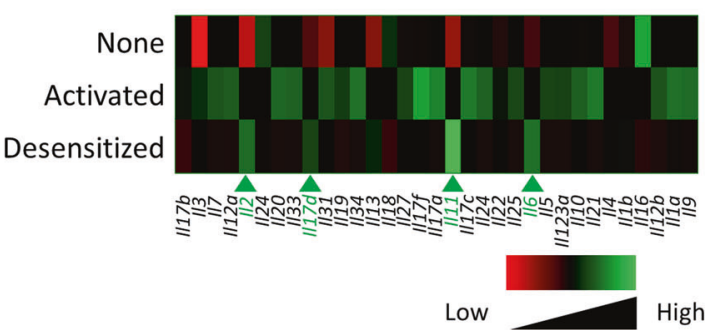

e

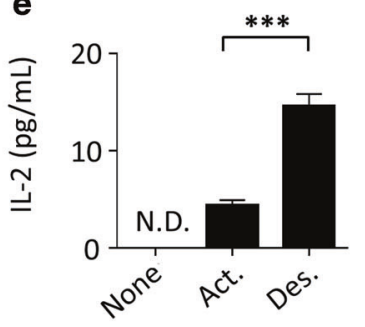

$\mathbf{f}$ g

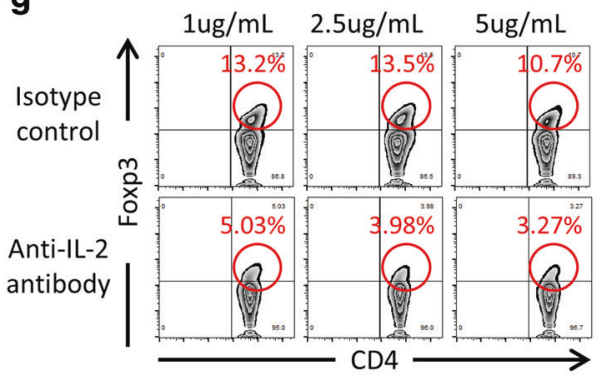

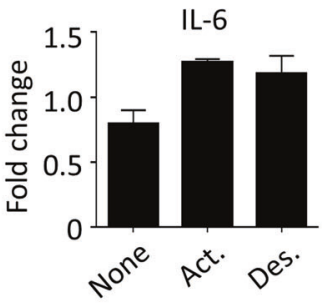

h
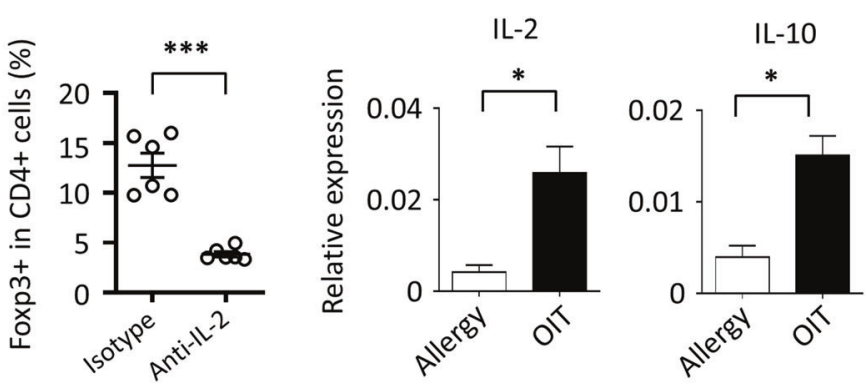

Fig. 6 Foxp3 Treg expansion by desensitized regulatory mast cells. a DNP-lgE bound (None), antigen-stimulated (Activation), or desensitized (Desensitization) bone marrow MCs (BMMCs) were co-cultured with $\mathrm{CD}^{+}{ }^{+} \mathrm{T}$ cells and expansion of the Foxp3 ${ }^{+} \mathrm{CD} 4^{+} \mathrm{T}$ cell population was analyzed by flow cytometry and cell sorting. Numbers indicate percentages of Foxp $3^{+}$among all CD4 ${ }^{+} \mathrm{T}$ cells. $\mathbf{b}$ lgE-bound and desensitized BMMCs and CD4 ${ }^{+}$T cells were co-cultured under separated conditions in transwells. Percentages of Foxp $3^{+}$cells among all $\mathrm{CD}^{+} \mathrm{T}$ cells are shown. c Gene microarray was performed with DNP-IgE bound (None), antigen-stimulated (Activated), and desensitized BMMCs. Shown is a heatmap representative of entities termed cytokines. d Expression of the genes encoding IL-2 and IL-6 was analyzed by quantitative RT-PCR. Data are shown as means \pm SEM. Act., activated; Des., desensitized. e IL-2 production was analyzed by ELISA. Data are shown as means \pm SEM. ${ }^{* *} P<0.001$ (all groups, $n=5$ ). $f \mathrm{IL}-2$ production from $\mathrm{hPBMC}$ was analyzed by ELISA. Data are shown as means $\pm \mathrm{SEM}$; all groups, $n=3$. g Percentages of Foxp $3^{+}$cells in coculture of desensitized BMMCs are shown. Isotype or anti-IL-2 antibody was added. $\mathbf{h}$ Gene expression of in vivo sorted MCs was analyzed by quantitative RT-PCR. Each result was normalized against the expression of Gapdh. Data are shown as means \pm SEM, ${ }^{* * *} P<0.01,{ }^{*} P<0.05$.

Treg cells and direct inhibition of Th2 pathway for the efficient induction of oral unresponsiveness against food allergy. However, in in vitro desensitized MCs we were unable to find upregulation of IL-10 (data not shown). In relation to this, it has been shown that IgG1-FcyRIII pathways induce IL-10 production by MCs in contact dermatitis. ${ }^{50}$ IL-4 stimulation enhances the production levels of FcyRIII and crosslinking with antigen-specific IgG1 induces IL-10 production. ${ }^{50,51}$ Both allergen-specific $\operatorname{lgE}$ and IgG antibodies have been at the center of discussions of the desensitization of MCs. ${ }^{52}$ An increase in the levels of 
allergen-specific lgG antibodies has been suggested to be associated with the desensitization of allergic responses. ${ }^{42}$ Indeed, the administration of allergen-specific IgG antibodies to a mouse model of food allergy suppressed MC activation via FcyRllb. ${ }^{42}$ The involvement of IgG-FcyRllb or FcyRIII pathways in OIT in vivo cannot be ignored in terms of both the inhibition of $\mathrm{MC}$ degranulation and the production of IL-10 by MCs.

In an airway inflammation model, IL-33 stimulation induced IL-2 production by MCs and resulted in limitation of inflammation. ${ }^{20}$ In a skin inflammation model, IL-2 release by MCs was induced by IL33 and further enhanced by IgE stimulation. ${ }^{35}$ However, mice in an IL-33-deficiency food allergy model had less severe signs than WT mice, indicating that IL-33 causes allergy rather than suppression in food allergy. ${ }^{53}$ IL-33 promotes food anaphylaxis in epicutaneously sensitized mice by targeting MCs. ${ }^{53}$ Here, we found no difference in IL-33 expression between allergic and OIT-treated intestinal MCs (Supplementary Fig. 9a). Indeed, we further examined this point by utilizing IL-33-deficient MCs and CD4 $T$ cells that were deficient in ST2, the receptor for IL-33 (Supplementary Fig. 6b). Moreover, coculture of desensitized IL33-deficient MCs with $\mathrm{CD}^{+}{ }^{+} \mathrm{T}$ cells still induced Foxp3 ${ }^{+}$Tregs. Thus, the induction of Tregs by desensitized regulatory MCs occurred via an IL-2-dependent but IL-33-independent pathway (Supplementary Fig. 9b).

The molecular mechanisms underlying desensitization-induced IL-2 production was not fully elucidated here. It has recently been found that desensitization of MCs inhibits calcium flux and suppress degranulation, with modulation of the cytoskeleton. ${ }^{54}$ In our recent and separate study, we also found partial internalization of surface lgE and its receptor FceRI by desensitization in vitro (data not shown); however, this reduced amount of FceRI is still capable of transducing signals. ${ }^{54}$ This implies that continuous stimulation by $\mathrm{Ag}-\mathrm{lgE}$ complex modulates FceRI signal transduction, resulting in a functional change in MCs. Taken together, these pieces of evidence imply the existence of unique and as-yetunelucidated cascades that regulate MC functions, including the shift from pathogenic to regulatory behaviors and the consequent induction of IL-2 and IL-10, producing "regulatory MCs" via constant stimulation from $\operatorname{lgE}$ and its receptor pathway. In addition, accumulated evidence from other studies and ours reveals that inflammatory cytokines from MCs are involved in the onset of chronic inflammatory disorders in various tissues and organs. ${ }^{25,55}$ The conversion of MC function from pathogenic to regulatory might be a critical approach to curing chronic inflammation beyond allergic diseases. Further analysis is therefore required to uncover the important role of allergen-lgEcomplex-mediated signaling in the conversion from pathogenic to beneficial MCs.

In summary, our results demonstrated that activated and degranulated MCs were essential pathological elements for the development of allergic diarrhea. However, OIT with an antigendose-escalation protocol effectively induced oral unresponsiveness against allergen-induced allergic diarrhea by the conversion of activated pathogenic MCs to desensitized regulatory MCs. Thus, OIT caused desensitized regulatory MCs to produce IL-2 for the expansion of Treg cell populations and IL-10 for the inhibition of allergic responses, whereas pathogenic Th2 cytokine production was inhibited (Supplementary Fig. 11). Our findings provide new insights into the pathogenic and beneficial aspects of MCs, which can be manipulated by the appropriate form of OIT to control allergic responses, including allergic diarrhea, through the coordinated cellular cascade of regulatory MCs and Treg cells.

\section{MATERIALS AND METHODS}

Mice

Female mice (age, 7-10 weeks) were used. BALB/c mice were purchased from CLEA Japan (Tokyo, Japan). Mas-TRECK mice (mice with deletion of MCs via IL4 enhancer elements upon diphtheria toxin treatment) were gifted as previously described. ${ }^{22}$ BALB/C background IL-33- and ST2-deficient mice were a gift from Dr. S. Akira (Osaka University). MC-deficient $K i t^{W-s h / W-s h}$ mice were obtained from Dr. H. Suto (Atopy Research Center, Juntendo University, Japan) and backcrossed at least seven times on a BALB/c background. All mice were maintained under specificpathogen-free conditions at the experimental animal facility of the institutes. All experiments were approved by the Animal Care and Use Committee of the University of Tokyo and Chiba University.

\section{Food allergy and OIT}

Mice were pre-sensitized with $1 \mathrm{mg}$ of ovalbumin (OVA) (Fraction V, Sigma Chemical Co., St. Louis, MO, USA) in complete Freund's adjuvant (CFA, Difco Laboratories, Detroit, MI, USA) by subcutaneous injection as described previously. ${ }^{56}$ After 1 week, the sensitized mice were challenged three times a week for several weeks with $50 \mathrm{mg}$ of orally administered OVA in phosphatebuffered saline (PBS). In this state, the mice were defined as the "allergy group." Mas-TRECK mice were injected with $150 \mu \mathrm{L}$ of 1 $\mu \mathrm{g} / \mathrm{mL}$ diphtheria toxin (Sigma-Aldrich, St Louis, MO, USA) intraperitoneally for 5 consecutive days and continued every other day as described previously. ${ }^{25}$ All mice used in the OIT procedure were first confirmed to show allergic diarrhea upon oral challenge with $25 \mathrm{mg}$ raw OVA. The next day, OIT was performed by using the following protocols. In dose-escalation OIT, we used a modified previously reported protocol ${ }^{57,58}$ to develop an OIT murine model that more closely resembled the human clinical scenario. OVA was heated to $100^{\circ} \mathrm{C}$ for $5 \mathrm{~min}$. Increasing doses of heated OVA in PBS were given intragastrically daily for 8 days, at $0.5 \mathrm{mg}$ (day 1), $1 \mathrm{mg}$ (day 2), $2 \mathrm{mg}$ (day 3), $4 \mathrm{mg}$ (day 4), $8 \mathrm{mg}$ (day 5), $12 \mathrm{mg}$ (day 6), $18 \mathrm{mg}$ (day 7), and $25 \mathrm{mg}$ (day 8); thereafter mice daily received $25 \mathrm{mg}$ of unheated OVA during the maintenance phase (36 days). Mice that had completed OIT were defined as the "OIT group".

Stool status was evaluated by using an appearance scale and by quantifying the water content (see Supplementary Fig. $2 \mathrm{~d}$ and e). Water content was determined by measuring the difference between the initial fecal weight and the dry weight. ${ }^{59}$ We putted the feces in closed container with silicagel, and the dry weight was measured on the fifth day.

\section{Cell collection and fluorescence-activated cell sorting (FACS) analysis}

Mononuclear cells were isolated from colonic lamina propria and Peyer's patches, as previously described. ${ }^{25}$ Briefly, epithelium was dissociated by using $0.5 \mathrm{mM}$ EDTA and the tissues were further treated with $1.25 \mathrm{mg} / \mathrm{mL}$ of collagenase at $37^{\circ} \mathrm{C} .{ }^{25}$ To collect mononuclear cells from mesenteric lymph nodes and spleen, the tissues were mashed mechanically and filtered through $70 \mu \mathrm{m}$ mesh. Lymphocyte separation medium (MP Biomedicals, Santa Ana, CA, USA) was used to isolate peripheral blood mononuclear cells (PBMCs).

For flow cytometric analysis, cells were incubated with $5 \mu \mathrm{g} / \mathrm{mL}$ of an anti-CD16/32 antibody (Fc block, BD Pharmingen, San Diego, CA) for $5 \mathrm{~min}$ and stained for $30 \mathrm{~min}$ at $4{ }^{\circ} \mathrm{C}$ with fluorescencelabeled antibodies (Abs) specific for c-kit (2B8), CD25 (3C7), CD45 (30F-11), CD63 (5A9), ${ }^{11}$ RORyt (Q31-378) (BD Pharmingen), and FceRla (MAR-1) and Foxp3 (FJK-16s) (eBioscience, San Diego, CA). CD4 (RM4-5), CD11b (M1/70), CD11c (N418), CD39 (Duha59), CD45 (30F11), CD49b (DX5), CD73 (TY/11.8), CXCR5 (L138D7), PD-1 (RMP1-30), GATA3 (16E10A23), and Tim-4 (F315G3) were purchased from BioLegend (San Diego, CA). Cells were analyzed by using FACSCalibur, FACSCanto II, and FACSAria III flow cytometry systems (Becton Dickinson, San Jose, CA, USA). The full gating strategies for MCs is shown in Supplementary Fig. 10. 
Quantitative real-time PCR and microarray analysis

Total RNA was prepared by using TRIzol (Thermo Fisher scientific, Waltham, MA, USA) and reverse-transcribed by using a Superscript VILO CDNA synthesis kit (Invitrogen, Carlsbad, CA, USA), as previously described. ${ }^{55}$ Quantitative reverse transcription-polymerase chain reaction (RT-PCR) was performed with LightCycler 480 II (Roche, Basel, Switzerland) and the Universal Probe Library (Roche). Microarray analysis was performed as described in our previous report. ${ }^{25}$ Briefly, MCs were sorted, and total RNA was extracted from them with TRIzol. cRNA was hybridized with DNA probes on a GeneChip Mouse Genome array (Agilent, Santa Clara, CA, USA). Data were analyzed with GeneSpring software (Agilent). ${ }^{25}$

In vivo antibody treatment study

Anti-mouse CD25 mAb (PC61, rat lgG1) for cell depletion and rat IgG for control treatment were purchased from Bio X Cell (Boston, MA, USA). Mice were intraperitoneally injected four times (days 9 , 13,17 , and 20) with $250 \mu \mathrm{g}$ of anti-CD25 mAb.

Cell culture and stimulation

About $95 \%$ purity of bone marrow MCs (BMMCs) were obtained as previously described ${ }^{11}$ (Supplementary Fig. 5). Cells were sensitized overnight with anti-dinitrophenyl (DNP) $\operatorname{lgE}(0.25 \mu \mathrm{g} / \mathrm{mL})$. The next day, the cells were washed to eliminate the excess of unbound $\mathrm{lgE}$ and resuspended at $37^{\circ} \mathrm{C}$ in $100 \mu \mathrm{L}$ of fresh medium with $5 \mathrm{ng} / \mathrm{mL} \mathrm{IL-3}$. For desensitization, cells were treated as described in the previous report. ${ }^{38}$ Briefly, DNP-human serum albumin (HSA) was added every $10 \mathrm{~min}$ for desensitization in $200 \mu \mathrm{L}$ culture condition $(50 \mathrm{pg}, 250 \mathrm{pg}, 250 \mathrm{pg}, 500 \mathrm{pg}, 500 \mathrm{pg}$, $1 \mathrm{ng}, 2 \mathrm{ng}, 8 \mathrm{ng}, 16 \mathrm{ng}, 17.5 \mathrm{ng}$ ); the cells were then stimulated with $80 \mathrm{ng}$ for $1 \mathrm{~h} .{ }^{38}$ For in vitro coculture analysis, MCs were presensitized with anti-DNP $\operatorname{lgE}(0.25 \mu \mathrm{g} / \mathrm{mL})$ overnight without antigen; they were then co-cultured for 3 days at $37^{\circ} \mathrm{C}$ in PBS with $8 \times 10^{5} \mathrm{CD}^{+} \mathrm{T}$ cells isolated from the spleen and mesenteric lymph nodes with MojoSort (Biolegend); the plates were precoated with $0.125 \mu \mathrm{g} / \mathrm{mL}$ anti-CD3E antibody (BD Pharmingen).

\section{OVA-specific antibody ELISA and cytokine ELISA}

For detection of OVA-specific lgE levels in sera, each serum sample was processed with an antigen-specific IgE ELISA kit (Fujifilm, Gunma, Japan) in accordance with the manufacturer's instructions. Mouse IL-2 production and mouse mast cell protease-1 (mMCP-1) in sera were detected by using the respective ELISA kits (eBioscience, San Diego, CA) in accordance with the manufacturer's instructions.

\section{ChIP assay}

The antibodies used for chromatin immunoprecipitation (ChIP) assay were anti-trimethylhistone H3-K4 (AR-0169; Bio Rad, Hercules, CA) and anti-acetyl-histone H3-K27 (C15410174; Diagenode, Denville, NJ).

ChIP experiments using anti-trimethylhistone $\mathrm{H} 3-\mathrm{K} 4$, antiacetylhistone $\mathrm{H} 3-\mathrm{K} 27$, or control $\mathrm{Ab}$ were performed with Dynabeads (Invitrogen) as previously described. ${ }^{60}$ In brief, $5 \times$ $10^{6}$ cells were fixed in $1 \%$ paraformaldehyde at $37^{\circ} \mathrm{C}$ for $10 \mathrm{~min}$. Cells were sedimented, washed, and lysed with sodium dodecyl sulfate (SDS) lysis buffer (50 mM Tris-HCl, 1\% SDS, 10 mM EDTA, 1 $\mathrm{mM}$ phenylmethylsulfonyl fluoride (PMSF), $1 \mathrm{mg} / \mathrm{mL}$ aprotinin, and $1 \mathrm{mg} / \mathrm{mL}$ leupeptin). The lysates were sonicated to reduce the DNA lengths to between 200 and $1000 \mathrm{bp}$. The soluble fraction was diluted in ChIP dilution buffer and incubated overnight at $4{ }^{\circ} \mathrm{C}$ with $\mathrm{Ab}$ conjugated with Dynabeads proteins $\mathrm{A}$ and $\mathrm{G}$. The immune complexes were then captured by using a magnet and washed with low-salt, high-salt, $\mathrm{LiCl}$, and Tris-EDTA wash buffer. Enriched chromatin fragments were eluted with elution buffer $\left(0.1 \mathrm{M} \mathrm{NaHCO}_{3}\right.$ containing $1 \%$ SDS). The eluted materials were incubated at $65^{\circ} \mathrm{C}$ for $6 \mathrm{~h}$ to reverse the formaldehyde cross-links and then treated with RNase $A(10 \mathrm{mg} / \mathrm{mL})$ and Proteinase $\mathrm{K}(40$ $\mathrm{mg} / \mathrm{mL}$ ). DNA was extracted with a QIAquick PCR purification kit (Qiagen, Hilden, Germany). The total input DNA (cellular DNA without immunoprecipitation) was purified in parallel. A real-time quantitative PCR analysis was performed by using the StepOnePlus Real-Time PCR System (Thermo Fisher Scientific) via the comparative cycle threshold method with TaqMan probes (Thermo Fisher Scientific) and primers. To calculate the enrichment of each protein to a particular target DNA, we divided the values obtained for each target by the amount of the corresponding target in the input fraction. ${ }^{60}$ All of the results are expressed as percentages of input DNA.

\section{ChIP-sequencing and Illumina sequencing}

Ab-specific immunoprecipitates and total input DNA samples were prepared by using a NEBNext ChIP-Seq [ChIP with massive parallel sequencing] Library Prep Reagent Set for Illumina. ${ }^{60}$ Adaptorligated DNA was recovered by using AMPure XP Beads (Beckmancoulter, Brea, CA). This DNA was then amplified by 15 cycles of PCR and again recovered by using AMPure XP Beads. Fifty cycles of sequencing reaction were performed on an Illumina HiSeq 1500 system (Illumina, San Diego, CA). Read sequences (50 bp) were then aligned to the $\mathrm{mm} 10$ mouse reference genome (University of California, Santa Cruz, July 2011) by using Bowtie. ${ }^{61}$ Each aligned read sequence was extended to $120 \mathrm{bp}$ to efficiently detect duplicate reads aligned to identical locations. These $120 \mathrm{bp}$ tags were used for further analyses (of BED files). MACS ${ }^{62}$ (modelbased analysis of (ChIP-Seq) was used for peak calling and visualization of binding, with the parameters set as follows: window size $=300$, gap size $=300$, and false discovery rate $=0.01 .^{60}$

\section{Human PBMC analysis}

Human peripheral blood CD34 ${ }^{+}$cells (Stem Cell Technologies, Vancouver, British Columbia, Canada) were cultured in serum-free Iscove's methylcellulose medium (Stem Cell Technologies) and Iscove's Modified Dulbecco's Medium containing recombinant ( $r$ ) human (h) stem cell factor (PeproTech EC, London, England) at $200 \mathrm{ng} / \mathrm{mL}$ and rhlL-6 (PeproTech EC) at $50 \mathrm{ng} / \mathrm{mL}$, as previously described. ${ }^{63}$ The number and purity of cultured MCs were confirmed by using FACS. ${ }^{64}$ Cells were stimulated with $0.25 \mu \mathrm{g} /$ $\mathrm{mL}$ of anti-hapten 4-hydroxy-3-nitrophenyl acetyl (Absolute Antibody, Oxford, UK), and increasing doses of NP-BSA (Biosearch Technologies, Novato, CA) $(2.5,12.5,12.5,25,25,50,100,200,400$, 800 , and $875 \mathrm{pg}$ ) were added every $10 \mathrm{~min}$ for desensitization; the cells were then stimulated with $10 \mathrm{ng}$ NP-BSA (Biosearch Technologies) for $1 \mathrm{~h}$ and then cultured overnight. IL-2 production in the culture supernatant was detected by using a high-sensitivity human IL-2 ELISA kit (Abcam, Cambridge, UK). These experiments were approved by the Ethics Committee of Juntendo University.

\section{Statistical analysis}

Statistical analysis was performed using the unpaired, two-tailed Student's $t$ test. All statistical analyses were conducted with Prism 7 (GraphPad Software, San Diego, CA, USA). A difference of $P<$ 0.05 was considered to be statistically significant. Error bars in figures indicate SEM.

\section{ACKNOWLEDGEMENTS}

We thank Dr. T. Kitamura (University of Tokyo) for the constructive discussions and for providing reagents; Dr. H. Suto (Atopy Research Center, Juntendo University) for providing $\mathrm{Kit}^{\mathrm{W} \text {-sh/W-sh }}$ mice; and Yuta Kogure, Kaoru Shimada, Yoshinao Konuma and Daiki Yamamoto (University of Tokyo) and Masako Morimoto (Chiba University) for technical support. This work was supported by grants from The Ministry of Education, Culture, Sports, Science, and Technology for Translational Research Network Program (at the University of Tokyo) Seeds A (Y.K.), B (H.K.), and C (H.K.), and LEADER (Y.K.); the Japan Agency for Medical Research and Development for CREST (H.K.) and PRIME (20gm6010012h0004 and 20gm6210024h0001 to Y.K.); the Japan Society for the Promotion of Science for a Grant-in Aid for Scientific Research S [18H05280 to H.K.] 
and Scientific Research B [19H03450 to Y.K.], Young Scientists A [16H06243 to Y.K.], Challenging Exploratory Research [17K19550 and 19K22634 to Y.K.], Funds for the Promotion of Joint International Research [18KK0432 to Y.K.], Science and Technology Research Partnership for Sustainable Development [H.K.]; the Joint Research Project of the Institute of Medical Science, University of Tokyo (J.K.); the Senri Life Science Foundation [Y.K.], the Mochida Memorial Foundation for Medical and Pharmaceutical Research [Y.K.], the Takeda Science Foundation [Y.K.], the Uehara Memorial Foundation [Y.K.], the Sumitomo Foundation (Y.K.), the Naito Foundation (Y.K), the Kato Memorial Bio-Science Foundation (Y.K.), the Yakult Bio-Science Foundation, and NipponHam Foundation (Y.K.); and the Chiba University - UC San Diego Center for Mucosal Immunology, Allergy, and Vaccines (H.K.).

\section{AUTHOR CONTRIBUTIONS}

Y.T. and Y.K. conducted the research and performed in vitro and in vivo experiments; S.M., F.A., Y.S., K.S., M.N., K.F., M.K., and K.H. conducted in vivo experiments. M.K., N.T., S.U., J. Kunisawa, S.A., T.N., T.T., and H.K. contributed to experimental design and data analysis; I.K., A.K., S.T., Y.O., and J. Kitaura conducted human mast cell analysis; and Y. K. and H.K. supervised the project and wrote the paper. All authors approved the final version of the paper.

\section{ADDITIONAL INFORMATION}

The online version of this article (https://doi.org/10.1038/s41385-020-00358-3) contains supplementary material, which is available to authorized users.

Competing interests: The authors declare no competing interests.

Publisher's note Springer Nature remains neutral with regard to jurisdictional claims in published maps and institutional affiliations.

\section{REFERENCES}

1. Longo, G., Berti, I., Burks, A. W., Krauss, B. \& Barbi, E. IgE-mediated food allergy in children. Lancet 382, 1656-1664 (2013).

2. Sicherer, S. H. Epidemiology of food allergy. J. Allergy Clin. Immunol. 127, 594-602 (2011).

3. Lieberman, P. et al. The diagnosis and management of anaphylaxis practice parameter: 2010 update. J. Allergy Clin. Immunol. 126, 477-480.e471-442 (2010).

4. Yamani A., et al. Dysregulation of intestinal epithelial CFTR-dependent $\mathrm{Cl}(-)$ ion transport and paracellular barrier function drives gastrointestinal symptoms of food-induced anaphylaxis in mice. Mucosal Immunol. https://doi.org/10.1038/ s41385-020-0306-6. [Ebup ahead of print] (2020).

5. Melendez, A. J. et al. Inhibition of Fc epsilon Rl-mediated mast cell responses by ES-62, a product of parasitic filarial nematodes. Nat. Med. 13, 1375-1381 (2007).

6. Galli, S. J. \& Tsai, M. IgE and mast cells in allergic disease. Nat. Med. 18, 693-704 (2012).

7. Brown, S. G. et al. Anaphylaxis: clinical patterns, mediator release, and severity. J. Allergy Clin. Immunol. 132, 1141-1149.e1145 (2013).

8. Soter, N. A., Austen, K. F. \& Wasserman, S. I. Oral disodium cromoglycate in the treatment of systemic mastocytosis. N. Engl. J. Med. 301, 465-469 (1979).

9. Harvima, I. T. et al. Molecular targets on mast cells and basophils for novel therapies. J. Allergy Clin. Immunol. 134, 530-544 (2014).

10. McLeod, J. J., Baker, B. \& Ryan, J. J. Mast cell production and response to IL-4 and IL-13. Cytokine 75, 57-61 (2015).

11. Kurashima, Y. et al. Sphingosine 1-phosphate-mediated trafficking of pathogenic Th2 and mast cells for the control of food allergy. J. Immunol. 179, 1577-1585 (2007).

12. Kweon, M. N., Yamamoto, M., Kajiki, M., Takahashi, I. \& Kiyono, H. Systemically derived large intestinal CD4(+) Th2 cells play a central role in STAT6-mediated allergic diarrhea. J. Clin. Investig. 106, 199-206 (2000).

13. Akdis, M. \& Akdis, C. A. Mechanisms of allergen-specific immunotherapy: multiple suppressor factors at work in immune tolerance to allergens. J. Allergy Clin. Immunol. 133, 621-631 (2014).

14. Larche, M., Akdis, C. A. \& Valenta, R. Immunological mechanisms of allergenspecific immunotherapy. Nat. Rev. Immunol. 6, 761-771 (2006).

15. Blumchen, $K$. et al. Oral peanut immunotherapy in children with peanut anaphylaxis. J. Allergy Clin. Immunol. 126, 83-91.e81 (2010).

16. Wood, R. A. Oral Immunotherapy for Food Allergy. J. Investig. Allergol. Clin. Immunol. 27, 151-159 (2017).

17. Chinthrajah, R. S., Hernandez, J. D., Boyd, S. D., Galli, S. J. \& Nadeau, K. C. Molecular and cellular mechanisms of food allergy and food tolerance. J. Allergy Clin. Immunol. 137, 984-997 (2016).
18. Burks, A. W. et al. Oral immunotherapy for treatment of egg allergy in children. $N$. Engl. J. Med. 367, 233-243 (2012).

19. Leveson-Gower, D. B. et al. Mast cells suppress murine GVHD in a mechanism independent of CD4+CD25+ regulatory T cells. Blood 122, 3659-3665 (2013).

20. Morita, H. et al. An Interleukin-33-Mast Cell-Interleukin-2 Axis Suppresses PapainInduced Allergic Inflammation by Promoting Regulatory T Cell Numbers. Immunity 43, 175-186 (2015).

21. Galli, S. J. et al. Approaches for analyzing the roles of mast cells and their proteases in vivo. Adv. Immunol. 126, 45-127 (2015).

22. Sawaguchi, M. et al. Role of mast cells and basophils in IgE responses and in allergic airway hyperresponsiveness. J. Immunol. 188, 1809-1818 (2012).

23. Keet, C. A. et al. The safety and efficacy of sublingual and oral immunotherapy for milk allergy. J. Allergy Clin. Immunol. 129, 448-455 (2012). 455 e441-445.

24. Khodoun, M. V. et al. Rapid polyclonal desensitization with antibodies to IgE and FcepsilonRlalpha. J. Allergy Clin. Immunol. 131, 1555-1564 (2013).

25. Kurashima, Y. et al. Extracellular ATP mediates mast cell-dependent intestinal inflammation through P2X7 purinoceptors. Nat. Commun. 3, 1034 (2012).

26. Dawicki, W., Li, C., Town, J., Zhang, X. \& Gordon, J. R. Therapeutic reversal of food allergen sensitivity by mature retinoic acid-differentiated dendritic cell induction of LAG3+CD49b-Foxp3- regulatory T cells. J. Allergy Clin. Immunol. 139, 1608-1620.e1603 (2017).

27. Noval Rivas, M. \& Chatila, T. A. Regulatory T cells in allergic diseases. J. Allergy Clin. Immunol. 138, 639-652 (2016).

28. Takayama, N., Igarashi, O., Kweon, M. N. \& Kiyono, H. Regulatory role of Peyer's patches for the inhibition of OVA-induced allergic diarrhea. Clin. Immunol. 123, 199-208 (2007).

29. Mabbott, N. A., Donaldson, D. S., Ohno, H., Williams, I. R. \& Mahajan, A. Microfold (M) cells: important immunosurveillance posts in the intestinal epithelium. Mucosal Immunol. 6, 666-677 (2013).

30. Esterhazy, D. et al. Classical dendritic cells are required for dietary antigenmediated induction of peripheral T(reg) cells and tolerance. Nat. Immunol. 17, 545-555 (2016).

31. de Vries, V. C. et al. Mast cells condition dendritic cells to mediate allograft tolerance. Immunity 35, 550-561 (2011).

32. Rodrigues, C. P. et al. Tolerogenic IDO(+) Dendritic Cells Are Induced by PD-1Expressing Mast Cells. Front. Immunol. 7, 9 (2016).

33. Feng, B. S. et al. Disruption of T-cell immunoglobulin and mucin domain molecule (TIM)-1/TIM4 interaction as a therapeutic strategy in a dendritic cell-induced peanut allergy model. J. Allergy Clin. Immunol. 122, 55-61 (2008). 61 e51-57.

34. Mazzini, E., Massimiliano, L., Penna, G. \& Rescigno, M. Oral tolerance can be established via gap junction transfer of fed antigens from CX3CR1(+) macrophages to CD103(+) dendritic cells. Immunity 40, 248-261 (2014).

35. Salamon, P. et al. IL-33 and IgE stimulate mast cell production of IL-2 and regulatory T cell expansion in allergic dermatitis. Clin. Exp. Allergy 47, 1409-1416 (2017).

36. Lu, L. F. et al. Mast cells are essential intermediaries in regulatory T-cell tolerance. Nature 442, 997-1002 (2006).

37. Oka, T., Rios, E. J., Tsai, M., Kalesnikoff, J. \& Galli, S. J. Rapid desensitization induces internalization of antigen-specific lgE on mouse mast cells. J. Allergy Clin. Immunol. 132, 922-932.e921-916 (2013).

38. Sancho-Serra Mdel, C., Simarro, M. \& Castells, M. Rapid IgE desensitization is antigen specific and impairs early and late mast cell responses targeting FcepsilonRI internalization. Eur. J. Immunol. 41, 1004-1013 (2011).

39. Suzuki, H. et al. Deregulated T cell activation and autoimmunity in mice lacking interleukin-2 receptor beta. Science 268, 1472-1476 (1995).

40. Sadlack, B. et al. Generalized autoimmune disease in interleukin-2-deficient mice is triggered by an uncontrolled activation and proliferation of CD4+ T cells. Eur. J. Immunol. 25, 3053-3059 (1995).

41. Josefowicz, S. Z., Lu, L. F. \& Rudensky, A. Y. Regulatory T cells: mechanisms of differentiation and function. Annu Rev. Immunol. 30, 531-564 (2012).

42. Burton, O. T., Tamayo, J. M., Stranks, A. J., Koleoglou, K. J. \& Oettgen, H. C. Allergen-specific IgG antibody signaling through FcgammaRilb promotes food tolerance. J. Allergy Clin. Immunol. 141, 189-201.e183 (2018).

43. Tunis, M. C., Dawicki, W., Carson, K. R., Wang, J. \& Marshall, J. S. Mast cells and IgE activation do not alter the development of oral tolerance in a murine model. $J$. Allergy Clin. Immunol. 130, 705-715.e701 (2012).

44. Bonnet, B. et al. Low-Dose IL-2 Induces Regulatory T Cell-Mediated Control of Experimental Food Allergy. J. Immunol. 197, 188-198 (2016).

45. Mizui, M. \& Tsokos, G. C. Targeting Regulatory T Cells to Treat Patients With Systemic Lupus Erythematosus. Front. Immunol. 9, 786 (2018).

46. He, X., Koenen, H. J., Slaats, J. H. \& Joosten, I. Stabilizing human regulatory T cells for tolerance inducing immunotherapy. Immunotherapy 9, 735-751 (2017).

47. Xie, M. M. et al. T follicular regulatory cells and IL-10 promote food antigenspecific IgE. J. Clin. Investig. 130, 3820-3832 (2020). 
48. Gowthaman U., et al. Identification of a T follicular helper cell subset that drives anaphylactic IgE. Science. 365 eaaw6433 (2019).

49. Chan, C. Y., StJohn, A. L. \& Abraham, S. N. Mast cell interleukin-10 drives localized tolerance in chronic bladder infection. Immunity 38, 349-359 (2013).

50. Grimbaldeston, M. A., Nakae, S., Kalesnikoff, J., Tsai, M. \& Galli, S. J. Mast cellderived interleukin 10 limits skin pathology in contact dermatitis and chronic irradiation with ultraviolet B. Nat. Immunol. 8, 1095-1104 (2007).

51. Chong, H. J. et al. IL-4 selectively enhances FcgammaRIII expression and signaling on mouse mast cells. Cell Immunol. 224, 65-73 (2003).

52. Caubet, J. C. et al. Significance of ovomucoid- and ovalbumin-specific $\lg E / \lg G(4)$ ratios in egg allergy. J. Allergy Clin. Immunol. 129, 739-747 (2012).

53. Galand, C. et al. IL-33 promotes food anaphylaxis in epicutaneously sensitized mice by targeting mast cells. J. Allergy Clin. Immunol. 138, 1356-1366 (2016).

54. Ang, W. X. et al. Mast cell desensitization inhibits calcium flux and aberrantly remodels actin. J. Clin. Investig. 126, 4103-4118 (2016).

55. Kurashima, Y. et al. The Enzyme Cyp26b1 Mediates Inhibition of Mast Cell Activation by Fibroblasts to Maintain Skin-Barrier Homeostasis. Immunity 40, 530-541 (2014).

56. Kunisawa, J. et al. Dietary omega3 fatty acid exerts anti-allergic effect through the conversion to 17,18-epoxyeicosatetraenoic acid in the gut. Sci. Rep. 5, 9750 (2015).

57. Leonard, S. A., Martos, G., Wang, W., Nowak-Wegrzyn, A. \& Berin, M. C. Oral immunotherapy induces local protective mechanisms in the gastrointestinal mucosa. J. Allergy Clin. Immunol. 129, 1579-1587.e1571 (2012).

58. Watanabe, $\mathrm{H}$. et al. Heat treatment of egg white controls allergic symptoms and induces oral tolerance to ovalbumin in a murine model of food allergy. Mol. Nutr. Food Res. 58, 394-404 (2014).

59. Code, C. F., Higgins, J. A. \& Orvis, A. L. The influence of motility on the rate of absorption of sodium and water from the small intestine of healthy persons. Gastroenterology 31, 708-715 (1956). discussion, 715-706.
60. Onodera, A. et al. Menin Controls the Memory Th2 Cell Function by Maintaining the Epigenetic Integrity of Th2 Cells. J. Immunol. 199, 1153-1162 (2017).

61. Langmead, B., Trapnell, C., Pop, M. \& Salzberg, S. L. Ultrafast and memory-efficient alignment of short DNA sequences to the human genome. Genome Biol. 10, R25 (2009).

62. Feng J., Liu T., Zhang Y. Using MACS to identify peaks from ChIP-Seq data. Curr. Protoc. Bioinform. Chapter 2: Unit 2.14 622-633 (2011).

63. Fujisawa, D. et al. Expression of Mas-related gene $\mathrm{X} 2$ on mast cells is upregulated in the skin of patients with severe chronic urticaria. J. Allergy Clin. Immunol. 134, 622-633.e629 (2014).

64. Takamori, A. et al. Identification of inhibitory mechanisms in pseudo-allergy involving Mrgprb2/MRGPRX2-mediated mast cell activation. J. Allergy Clin. Immunol. 143, 1231-1235.e1212 (2019).

(i) Open Access This article is licensed under a Creative Commons cc) Attribution 4.0 International License, which permits use, sharing adaptation, distribution and reproduction in any medium or format, as long as you give appropriate credit to the original author(s) and the source, provide a link to the Creative Commons license, and indicate if changes were made. The images or other third party material in this article are included in the article's Creative Commons license, unless indicated otherwise in a credit line to the material. If material is not included in the article's Creative Commons license and your intended use is not permitted by statutory regulation or exceeds the permitted use, you will need to obtain permission directly from the copyright holder. To view a copy of this license, visit http://creativecommons. org/licenses/by/4.0/.

(c) The Author(s) 2020 